\title{
Pulmonary embolism and coronavirus disease 2019: persistent pulmonary hypertension?
}

\author{
Alejandro Cruz-Utrilla1, Miguel Calderón-Flores², María P. Escribano-Subias ${ }^{1,3}$ \\ 1 Pulmonary Hypertension Unit, Cardiology Department, Hospital Universitario 12 de Octubre, Madrid, Spain \\ 2 Cardiology Department, Hospital Universitario 12 de Octubre, Madrid, Spain \\ 3 CIBER - Center for Biomedical Research Network, Madrid, Spain
}

Correspondence to: Alejandro Cruz Utrilla, MD, Pulmonary Hypertension Unit, Cardiology Department, Hospital Universitario 12 de Octubre, Avenida de Córdoba S/N, 28041 Madrid, Spain, phone: +34635765340 , email: alejandro.cruz@salud.madrid.org, Twitter: @AlexCruzUtrilla Received: April 27, 2020. Revision accepted: June 8, 2020 Published online: June 18, 2020. Kardiol Pol. 2020; 78 (9): 937-938 doi:10.33963/KP.15436 Copyright by the Author(s), 2020
A 47-year-old man with an unremarkable medical history was admitted to the emergency department because of ageusia, fever, cough, and dyspnea. The symptoms started 10 days before presentation. At that time, the patient showed acute hypoxemic respiratory failure and fever of up to $40^{\circ} \mathrm{C}$. Lymphopenia with a lymphocyte count of $0.6 \times 10^{3} / \mu \mathrm{l}$, a C-reactive protein level of $25.7 \mathrm{mg} / \mathrm{dl}$, and a D-dimer level of $354 \mu \mathrm{g} / \mathrm{l}$ were noted. On electrocardiography, the patient presented sinus tachycardia at $110 \mathrm{bpm}$ with left anterior bundle-branch block. Chest X-ray showed peripheral, bilateral infiltrates (FIGURE 1A). In the context of the severe acute respiratory syndrome coronavirus 2 (SARS-CoV-2) pandemic, the patient was diagnosed with bilateral coronavirus disease 2019 (COVID-19) pneumonia and ceftriaxone, azithromycin, and hydroxychloroquine were initiated. Eventually, a real-time polymerase chain reaction test for SARS-CoV-2, performed on a nasopharyngeal swab, yielded a positive result.

Two days later, the patient suddenly deteriorated and suffered from pleuritic pain. D-dimer levels peaked up to $52958 \mu \mathrm{g} / \mathrm{l}$. Computed tomography angiography was carried out and demonstrated the main pulmonary artery of $35 \mathrm{~mm}$ in diameter (FIGURE 1B), which was suggestive of significant pulmonary hypertension (PH), and bilateral pulmonary embolism (PE) in segmental arteries (FGURE1C and 1D). Extensive pulmonary parenchymal involvement was also observed. Despite the patient's hemodynamic stability at that time, he was admitted to the intensive care unit, requiring only mild supplemental oxygen supply. On transthoracic echocardiography performed during his stay in the intensive care unit, his systolic pulmonary artery pressure rose to $70 \mathrm{~mm} \mathrm{Hg}$. The examination was repeated 2 days before the patient's discharge and showed similar systolic pulmonary artery pressure, which confirmed significant $\mathrm{PH}$.

The patient was discharged on day 35. Due to mild hypoxemia and dyspnea on exertion, he was receiving hospital-at-home care for 2 weeks. During that time, oxygen therapy was finally withdrawn.

It is too early to assert what consequences will appear in the lungs or pulmonary arteries of the patient, but persistent $\mathrm{PH}$ could be one of them. Acute respiratory distress syndrome, which is often present in patients with COVID-19, could cause $\mathrm{PH}$ due to hypoxic vasoconstriction. Also, an increased prevalence of $\mathrm{PE}^{2}$ as a consequence of a high thrombotic risk has also been observed, which has been related to coagulation abnormalities and an enhanced inflammatory response against the virus. The presence of elevated levels of D-dimer and parameters such as interleukin 6 or ferritin have been associated with those reactions and have shown prognostic relevance. ${ }^{3}$ In this case, $\mathrm{PH}$ could be related to the acute episode of PE in addition to respiratory failure, but further assessment in a $\mathrm{PH}$-dedicated outpatient clinic is required to confirm this hypothesis. Additionally, not only persistent $\mathrm{PH}$ due to incomplete resolution of PE may cause chronic thromboembolic disease (group IV PH) but also PH due to lung parenchymal damage (group III) or pulmonary artery hypertension (group I) secondary to endothelial dysfunction could all be plausible causes of persistent $\mathrm{PH}$. These 3 hypotheses, however, need to be confirmed in further studies. A high suspicion index of $\mathrm{PH}$ is necessary in survivors with chronic dyspnea after SARS-CoV-2 infection-related pneumonia, acute respiratory distress syndrome, or PE. 

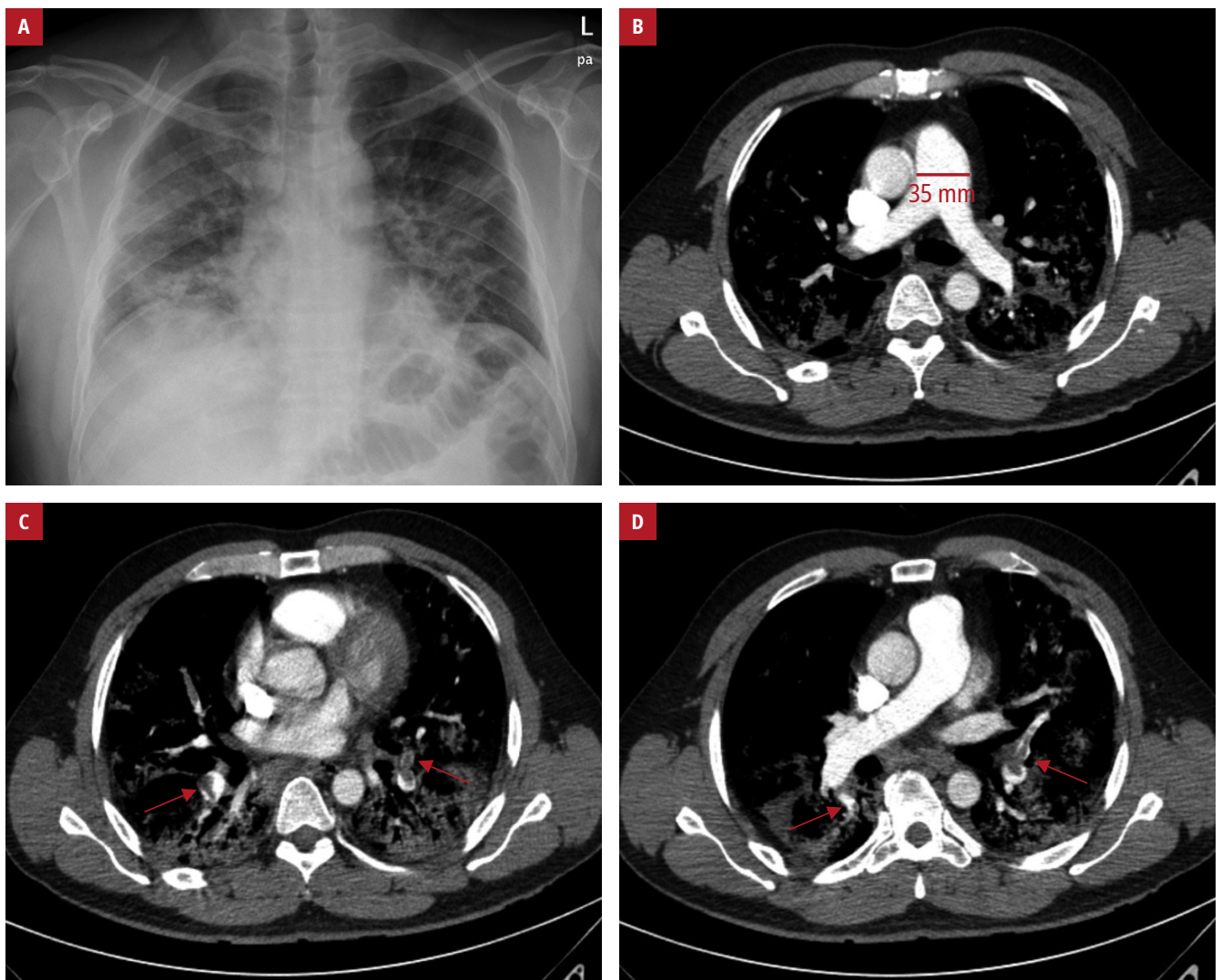

FIGURE 1 A - chest X-ray showing bilateral interstitial pneumonia; B - computed tomography angiography of the main pulmonary artery and the main branches. The main pulmonary artery is up to $35 \mathrm{~mm}$ in diameter, which is suggestive of significant pulmonary hypertension. C, D - computed tomography angiography demonstrating a thrombus in the bilateral segmental arteries (arrows)

\section{ARTICLE INFORMATION}

\section{CONFLICT OF INTEREST None declared.}

OPEN ACCESS This is an Open Access article distributed under the terms of the Creative Commons Attribution-NonCommercial-NoDerivatives 4.0 International License (CC BY-NC-ND 4.0), allowing third parties to download articles and share them with others, provided the original work is properly cited, not changed in any way, distributed under the same license, and used for noncommercial purposes only. For commercial use, please contact the journal office at kardiologiapolska@ptkardio.pl.

HOW TO CITE Cruz-Utrilla A, Calderón-Flores M, Escribano-Subias MP. Pulmonary embolism and coronavirus disease 2019: persistent pulmonary hypertension? Kardiol Pol. 2020; 78: 937-938. doi:10.33963/KP.15436

\section{REFERENCES}

1 Bikdeli B, Madhavan MV, Jimenez D, et al. COVID-19 and thrombotic or thromboembolic disease: implications for prevention, antithrombotic therapy, and follow-up. J Am Coll Cardiol. 2020; 75: 2950-2973.

2 Rotzinger DC, Beigelman-Aubry C, von Garnier C, Qanadli SD. Pulmonary embolism in patients with COVID-19: time to change the paradigm of computed tomography. Thromb Res. 2020; 190: 58-59.

3 Kollias A, Kyriakoulis KG, Dimakakos E, et al. Thromboembolic risk and anticoagulant therapy in COVID-19 patients: emerging evidence and call for action. $\mathrm{Br}$ J Haematol. 2020; 189: 846-847. 